\title{
Electrophysiological Effects of Cocaine in the Mesoaccumbens Dopamine System: Studies in the Ventral Tegmental Area
}

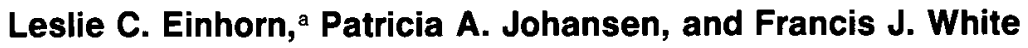 \\ Neuropsychopharmacology Laboratory, University of Illinois, Department of Psychology, Champaign, Illinois 61820
}

Extracellular single-cell recording and microiontophoretic techniques were used to characterize the effects of cocaine on the activity of mesoaccumbens A10 dopamine (DA) neurons in the rat ventral tegmental area (VTA), which have been implicated in the rewarding effects of this and other drugs of abuse. Because cocaine inhibits the reuptake of DA, norepinephrine (NE), and serotonin (5-HT), and exerts local anesthetic actions, the possible involvement of each of these various mechanisms in the effects of cocaine on A10 DA neurons was investigated. Intravenous administration of cocaine caused a significant, dose-dependent, partial inhibition (50-70\%) of the firing of antidromically identified mesoaccumbens DA neurons. Similar partial inhibition of A10 neurons was observed following intravenous administration of nomifensine, GBR-12909, and norcocaine, all of which inhibit DA reuptake. Neither the selective 5-HT uptake inhibitor fluoxetine nor the selective NE uptake inhibitor desmethylimipramine (DMI) inhibited the firing of A10 DA neurons. The local anesthetic agent procaine, which lacks DA uptake blocking efficacy, caused a slight, transient increase in firing rate. These results suggest that the effects of cocaine on A10 DA neurons are due to inhibition of DA reuptake, a conclusion that has been supported by several other findings. Pretreatment with reserpine to deplete vesicular stores of DA significantly reduced the ability of intravenous cocaine to suppress A10 DA neuronal activity. Microiontophoretic administration of cocaine caused only a weak (15$20 \%$ ) inhibition of the activity of A10 DA neurons, but significantly increased and prolonged the inhibition produced by iontophoretic DA. This effect was not observed with iontophoretically administered procaine. Iontophoresis of cocaine also significantly potentiated the inhibition of A10 DA activity caused by electrical stimulation of the nucleus accumbens (NAc). Both unilateral ibotenic acid lesions of the NAC and hemitransections of the brain rostral to the VTA significantly reduced the inhibitory effects of intravenous cocaine on A10 DA neurons, suggesting that both somato-

\footnotetext{
Received Feb. 24, 1987; revised June 15, 1987; accepted July 8, 1987.

This research was supported by USPHS Grant DA-04093 from the National Institutc on Drug Abusc and a Pharmaccutical Manufacturer's Association Foundation Research Starter Grant. We thank Eli Lilly \& Co. for their gift of fluoxetine, Hoescht-Roussel for nomifensine, Ravizza for sulpiride, and NOVO for generous supplies of GBR-12909. Norcocaine was provided by NIDA. We also thank Lisa Bednarz, Richard Brooderson, Don Golen, Sharon Gruber, Rob Mican, Marguerite Regan, and Robyn Thomas for technical assistance.

Correspondence should be addressed to Francis J. White, Ph.D., Neuropsychopharmacology Laboratory, Lafayette Clinic, 951 East Lafayette, Detroit, MI 48207.

a Present address: Curriculum in Neurobiology, University of North Carolina, Chapel Hill, NC 27514.

Copyright (C) 1988 Society for Neuroscience $0270-6474 / 88 / 010100-13 \$ 02.00 / 0$
}

dendritic impulse-regulating DA autoreceptors and inhibitory NAc-VTA feedback processes are involved in the effects of intravenous cocaine on A10 DA neurons. Therefore, it is hypothesized that the relatively weak inhibitory effects of cocaine on A10 DA neurons may represent a poor compensatory response to enhanced DA neurotransmission within the NAc, and may help to explain the extremely potent rewarding effects of this important drug of abuse.

During the past 15 years, cocaine use has risen dramatically and cocaine abuse has become a problem of considerable national concern (Kozell and Adams, 1986). Although a variety of sociologic, economic, and psychologic variables have undoubtedly led to the rise in the popularity of cocaine as a drug of recreational use, the potent rewarding effects of this compound are primarily responsible for its high abuse liability. Surprisingly little is known regarding the precise neuronal mechanisms by which cocaine induces its rewarding effects. Self-administration studies, conducted in a variety of species, have implicated dopamine-containing ncuronal pathways in the reinforcing properties of cocaine (Risner and Jones, 1976, 1980; deWit and Wise, 1977; Yokel and Wise, 1978; Wise, 1984). Moreover, several investigators (Roberts et al., 1977, 1980; Roberts and Koob, 1982; Goeders and Smith, 1983, 1986) have demonstrated a specific involvement of the mesolimbic and mesocortical dopamine (DA) systems, which originate in the ventral tegmental area (VTA; A10 DA neurons) and project primarily to the nucleus accumbens (NAc) (Andén et al., 1966; Ungerstedt, 1971) and medial prefrontal cortex (mPFC) (Thierry et al., 1973; Hökfelt et al., 1974; Lindvall et al., 1974). For example, 6-hydroxydopamine (6-OHDA) lesions of DA terminals in the NAc or of DA soma within the VTA attenuate cocaine self-administration, while similar injections into the caudate nucleus or substantia nigra pars compacta (i.e., the nigrostriatal DA system) do not (Roberts and Koob, 1982). Furthermore, injections of cocaine directly into the $\mathrm{MPFC}$ can support operant responding (Goeders and Smith, 1983), thereby suggesting a role for the mPFC DA system in cocaine reward (Goeders and Smith, 1983, 1986; however, see Martin-Iverson et al., 1986).

Cocaine is a sympathomimetic agent, which possesses both psychomotor stimulant (Scheel-Kruger et al., 1977) and local anesthetic properties (Carney, 1955). Cocaine inhibits the nerve terminal reuptake mechanism for the neurotransmitters DA, norepinephrine (NE), and serotonin (5-HT) (Ross and Renyi, 1967a, b; Snyder and Coyle, 1969; Heikkila et al., 1975). Because this reuptake process is the primary means by which synaptic monoamines are inactivated, cocaine increases synaptic concentrations of these neurotransmitters and thereby enhances 
monoaminergic neurotransmission. There also appear to be mechanisms for dendritic relcase and reuptakc of DA, and these mechanisms are thought to play a functional role in regulating DA neuronal activity (Björklund and Lindvall, 1975; Groves et al., 1975; Geffen et al., 1976; Wilson et al., 1977; Chéramy et al., 1981). Although less is known about these dendritic processes, it has been reported that the dendritic release and reuptake mechanisms for DA within the VTA are similar to nerve terminal mechanisms (Beart and McDonald, 1980; however, see Björkland and Lindvall, 1975). Therefore, it is possible that cocaine also blocks dendritic reuptake of DA and thereby increases extracellular concentrations of DA in the VTA, which would interact with somatodendritic impulse-regulating DA autoreceptors on mesoaccumbens DA cells (Wang, 1981 b; White and Wang, 1984a, b, 1986). The present experiments were designed to characterize the effects of cocaine on the electrophysiological properties of individual A10 DA neurons within the mesoaccumbens DA system.

\section{Materials and Methods}

Animals and preparations. Male Sprague-Dawley rats (bred in our animal care facilities from breeders obtained from Harlan, Indianapolis, IN) weighing between 225 and $325 \mathrm{gm}$ were used in all experiments. The rats were housed in groups of 2-4/cage with food and water available ad libitum and were maintained on a $12 / 12 \mathrm{hr}(0700 \mathrm{on} / 1900 \mathrm{off}) \mathrm{light} /$ dark cycle. Rats were anesthetized with chloral hydrate $(400 \mathrm{mg} / \mathrm{kg}$, i.p.), mounted in a stereotaxic apparatus (David Kopf Instruments, Tujunga, CA or Activational Systems, Warren, MI), and the scalp was retracted. During all experiments, body temperature was maintained at $37^{\circ} \mathrm{C}$ with a thermostatically controlled heating pad (Fintronics, Orange, CT). A latcral tail vcin was cannulatcd (25-gaugc nccdlc) for intravcnous administration of drugs and additional anesthetic. A burr hole was drilled in the skull over the VTA $(3.0 \mathrm{~mm}$ anterior to lambda, $0.5-1.0$ $\mathrm{mm}$ lateral to the midline) according to the atlas of Paxinos and Watson (1986), and the dura was retracted. All surgical procedures were performed in strict accordance with The NIH Guide for the Care and Use of Laboratory Animals.

Single-unit recording. For intravenous drug studies, extracellular neuronal activity was recorded through a single-barrel glass micropipette that had been pulled from $2.0 \mathrm{~mm}$ (O.D.) glass tubing with a vertical electrode puller (Narishige PE-2, Japan), broken back under a microscope to a tip diameter of approximately $1-2 \mu \mathrm{m}$, and filled with $2 \mathrm{M}$ $\mathrm{NaCl}$ saturated with $1 \%$ fast green dye (Fisher Scientific Co., St. Louis, $\mathrm{MO}$ ). For microiontophoretic experiments, extracellular neuronal activity was recorded through the center barrcl of a 5-barrcl micropipettc (R \& D Scientific Glass, Spencerville, MD), which was similarly pulled, broken to a tip diameter of 4-7 $\mu \mathrm{m}$, and filled as above. The in vitro impedance of these electrodes was usually 3-9 $\mathrm{M} \Omega$, measured at 135 $\mathrm{Hz}$ (Winston Electronics BL1000-B, San Francisco, CA).

For single-cell recording, electrical signals were led into a high-impedance amplifier, filtered (bandpass settings $100 \mathrm{~Hz}$ and $3 \mathrm{kHz}$ ), displayed on an oscilloscope (Tektronix R5110, Chicago, IL) and fed into a window discriminator (Fintronics WDR 420) that was set such that the standard output was triggered by individual action potentials. Integrated rate histograms generated by the analog output of the discriminator were plotted on a polygraph recorder (Gould 220, Chicago, IL). Electrical signals were also monitored by an audio amplifier (Grass AM8, Quincy, MA) which was driven by the oscilloscope. Recording electrodes were lowered through the brain with a hydraulic microdrive (David Kopf Instruments). The digital output of the window discriminator was led into a computer (Medical Systems Neurograph STA-1, Greenvale, NY), which determined average firing rates on-line and stored all data for future off-line analysis.

The A10 DA neurons were identified by anatomical location within the VTA (6.0-8.5 mm ventral from the cortical surface) and according to well-established electrophysiological criteria (Bunney et al., 1973; Wang, 1981a; Grace and Bunney, 1983a). These A10 DA neurons are characterized by (1) spontaneous firing rates of $1.0-10.0 \mathrm{~Hz}$, (2) either a slow, irregular firing pattern or a slow bursting pattern with decreasing spike amplitude within the burst, and (3) biphasic $(+/-)$ or triphasic
$(+/-/+)$ waveforms with long-duration action potentials $(>2.5 \mathrm{msec})$ and a characteristic notch in the ascending component of the initial positive wave.

Intravenous challenge experiments. For intravenous drug studies, each A10 DA neuron was recorded for at least 3-5 min prior to drug administration to determine stable basal firing rates. Cocaine, nomifensine, norcocaine, DMI, fluoxetine, GBR-12909, and procaine were administered at $60-90 \mathrm{sec}$ intervals such that each dose doubled the previously administered dose from 0.1 to $3.1 \mathrm{mg} / \mathrm{kg}$. The mean firing rate during the 60-90 sec interval between doses was determined and expressed as the percentage change from the basal firing rate. In some cases, the DA antagonist haloperidol was administered $(0.05-0.2 \mathrm{mg} / \mathrm{kg}$, i.v.) to reverse the effects of the various compounds and confirm (tentatively) DA receptor mediation of the agonist-induced suppression. Only one cell was recorded from each rat in all intravenous drug studies.

Time-course determinations. To study the recovery of A10 DA neurons from cocaine-induced inhibition, single bolus injections of cocaine were administered intravenously at doses of 0.5 and $1.0 \mathrm{mg} / \mathrm{kg}(n=$ $8 /$ group). The cells were held for as long as possible (at least $10 \mathrm{~min}$; range, 10-23 $\mathrm{min}$ ), and the percentage change from the basal firing rate was determined at 1 min intervals.

Reserpine pretreatment. To deplete vesicular stores of DA from the A10 DA neurons, a group of rats $(n=9)$ received intraperitoneal injections of reserpine $(5.0 \mathrm{mg} / \mathrm{kg}$, dissolved in a minimum of glacial acetic acid and diluted to the correct volume with $5.5 \%$ glucose solution, $\mathrm{pH} \mathrm{4.0)} 18-24 \mathrm{hr}$ prior to recording. Cumulative doses of cocaine were then administered intravenously and the percentage change from the basal firing rate was determined as described above. Control rats $(n=$ 9) received injections of the reserpine vehicle $18-24 \mathrm{hr}$ prior to recording.

Electrical stimulation. To identify A10 DA neurons projecting to the NAc (mesoaccumbens DA neurons), bipolar concentric stimulating electrodes (NE-100; David Kopf Instruments) were implanted into the NAc (anterior, $10.4 \mathrm{~mm}$; lateral, $1.3 \mathrm{~mm}$ ) ipsilateral to the recording site 7.0 $\mathrm{mm}$ below the cortical surface. Digital square-wave pulses $(0.05-1.8$ $\mathrm{mA} ; 0.15-0.5 \mathrm{mscc}$ ) were gencrated by a pulse gencrator (World Precision Instruments 1830) and photon-coupled stimulus isolation units (WPI 1850A). Criteria for antidromic spikes included (1) one antidromic spike per stimulus, (2) relatively constant latency $(<1 \mathrm{msec}$ drift), (3) ability to follow high-frequency stimulation (up to $50 \mathrm{~Hz}$ ), and (4) collision between evoked and spontaneous spikes occurring immediately prior to stimulus onset (Fuller and Schlag, 1976).

Stimulating electrodes were also used to determine the effects of electrical stimulation of the NAc on the neuronal activity of A10 DA neurons and its modification by cocaine. In these experiments, the same procedures were used as described above, with stimulation currents ranging from 0.5 to $3.0 \mathrm{~mA}$. Both temporal control of stimulation impulse and the generation of peristimulus time histograms (PSTHs) were performed with the Medical Systems STA-1 computer.

Microiontophoresis. For microiontophoretic application of drugs, onc of the 4 outer barrels of a 5-barrel micropipette was filled with $2 \mathrm{~m}$ $\mathrm{NaCl}$ and used for automatic current balancing (Salmoiraghi and Weight, 1967). The 3 other barrels contained various combinations of the following solutions: $\mathrm{GABA}, \mathrm{DA} \mathrm{HCl}$, cocaine $\mathrm{HCl}$, procaine $\mathrm{HCl}$, and sulpiride. All compounds were diluted to $0.01 \mathrm{~m}$ solutions ( $\mathrm{pH} \mathrm{4.0)}$, except for sulpiride, which was diluted to a $0.05 \mathrm{~m}$ solution ( $\mathrm{pH} 4.0$ ). Fiberglass strands were preloaded into each barrel such that the solutions would fill to the tip by capillarity (Tasaki et al., 1968). The in vitro impedance of the side barrels was typically 30-100 M 2 . Because all drug solutions were in cationic forms, a retaining current of $-10 \mathrm{nA}$ was continuously applied to the drug barrels to eliminate passive diffusion. Positive currents between 5 and $80 \mathrm{nA}$ were used to eject drugs. Iontophoretic ejection of drugs and current balancing were controlled automatically (Medical Systems BH-2). The percentage of inhibition produced by iontophoretic drug ejection was determined automatically (Medical Systems PDC-1) by comparing the mean firing rate during a $1 \mathrm{~min}$ ejection period to the $3-5 \mathrm{~min}$ predrug period used to determine basal rates.

Ibotenic acid lesions. To determine whether the effects of cocaine require postsynaptic DA receptors and forebrain feedback pathways from the NAc to the VTA, a group of rats $(n=8)$ received unilateral ibotenic acid lesions of the NAc intended to destroy neuronal somata without affecting fibers of passage (Schwartz et al., 1979). Chloral hydrate-anesthetized rats received a unilateral injection of 5-6 $\mu \mathrm{g}$ of ibotenic acid dissolved in PBS ( $\mathrm{pH} 7.4$ ). A total of $1.0 \mu \mathrm{l}$ was injected at 
Figure 1. Comparison of the effects of cocaine, procaine, and a variety of amine reuptake blockers on the firing of $\mathrm{A} 10$ dopamine (DA) neurons in the rat ventral tegmental area (VTA). Each drug was administered intravenously on a regimen in which each dose doubled the previously administered dose $(0.1,0.2$, $0.4 \mathrm{mg} / \mathrm{kg}$, etc.). Drugs used and sample sizes were cocaine $(C O C, 12)$, nomifensine (NOM, 12), GBR-12909 (GBR, 8), norcocaine $(N O R, 6)$, desmethylimipramine $(D M I, 6)$, fluoxetine $(F L U, 6)$ and procaine $(P R O, 8)$. Data points represent means; error bars are not shown to improve the clarity of the figure. In no case was the SEM $>8.2 \%$.

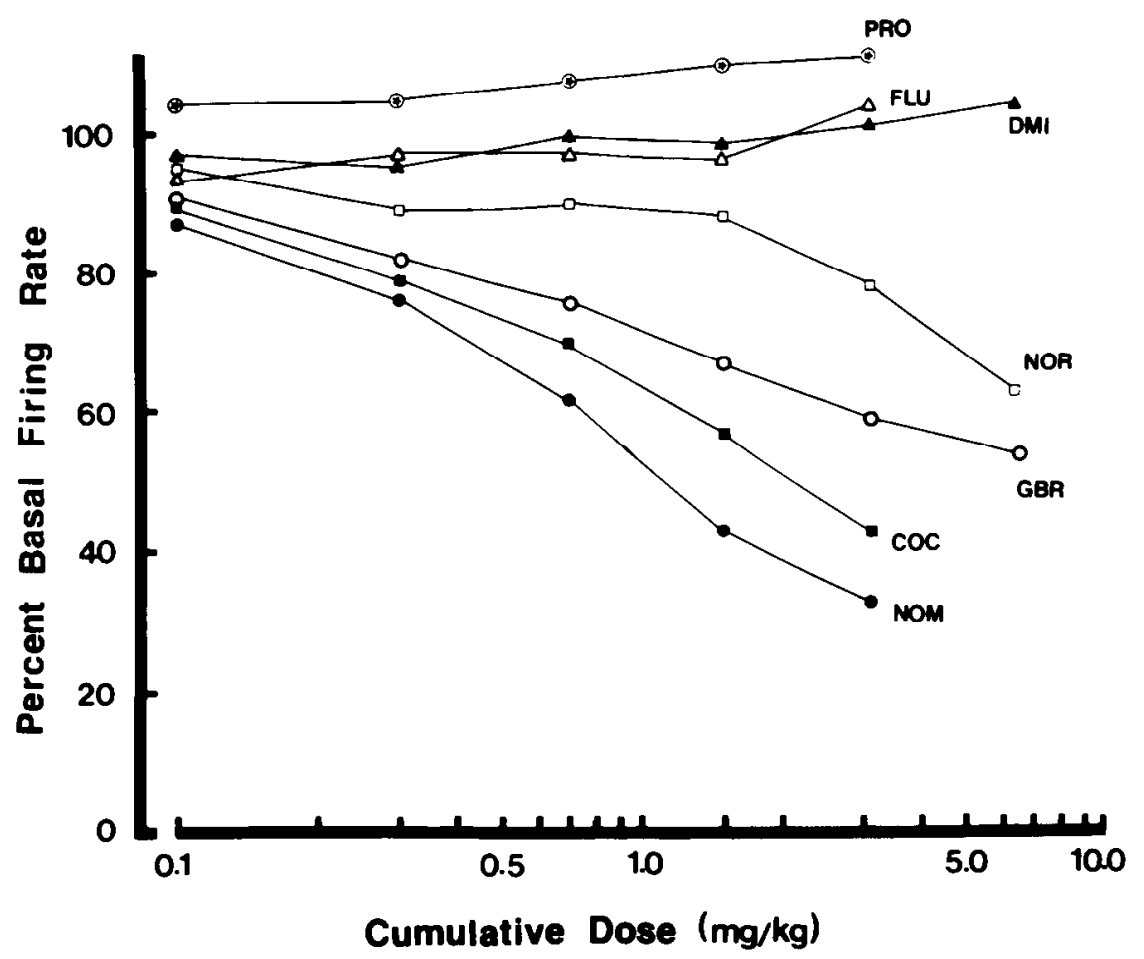

Roussel, Somerville, NJ), dopamine $\mathrm{HCl}$ (Calbiochem-Behring Corp., San Diego, CA), and sulpiride (Ravizza, Milan, Italy). All compounds used for parenteral injections, with the exception of haloperidol and reserpine, were dissolved in either deionized $\mathrm{H}_{2} \mathrm{O}$ or $0.9 \% \mathrm{NaCl}$. Haloperidol was first dissolved in a few drops of $10 \mathrm{~mm}$ citric acid; this was diluted with deionized $\mathrm{H}_{2} \mathrm{O}$ and the $\mathrm{pH}$ adjusted to 5.0 with $\mathrm{NaOH}$. Reserpine was dissolved as described above. All drugs used in intravenous studies were made fresh on the day of the experiment.

\section{Results}

Intravenous cocaine effects on mesoaccumbens A10 DA neurons

Intravenous administration of cocaine caused a significant $(F(4,44)=67.6, p<0.001)$, dose-dependent, partial $(50-70 \%)$ inhibition of the activity of antidromically identified mesoaccumbens DA neurons (Fig. 1). Of the 12 identified mesoaccumbens A10 DA cells tested, only 2 were completely inhibited by cocaine. The firing rate of one cell was increased (to $130 \%$ of control) following the first 3 doses of cocaine, but was inhibited by the last 2 doses (to $56 \%$ of control). At doses above $3.1 \mathrm{mg} /$ $\mathrm{kg}$, cocaine was fatal to all 4 rats tested. The DA antagonist haloperidol reversed the cocaine-induced suppression of the 8 cells tested (Fig. 4A). In contrast, neither the $\alpha-1 \mathrm{NE}$ antagonist prazosin $(n=3)$ nor the $\alpha-2 \mathrm{NE}$ antagonist piperoxane $(n=3)$ reversed the effects of cocaine (not shown).

\section{Time course of cocaine-induced inhibition}

Single-bolus intravenous injections of cocaine caused partial inhibition of most of the A10 DA neurons studied. Figure 2 compares the responses of A10 DA neurons to single doses of 0.5 and $1.0 \mathrm{mg} / \mathrm{kg}$ of cocaine (larger bolus doses were not tested because of their lethality). There was no significant difference $(F(1,12)=0.25$, n.s.) between the 0.5 and $1.0 \mathrm{mg} / \mathrm{kg}$ doses in the overall time-response curve. Note that by $10 \mathrm{~min}$ after the injection, the mean degree of inhibition had leveled off at 70$80 \%$ of basal firing rate in each group (Fig. 2). Several cells were 


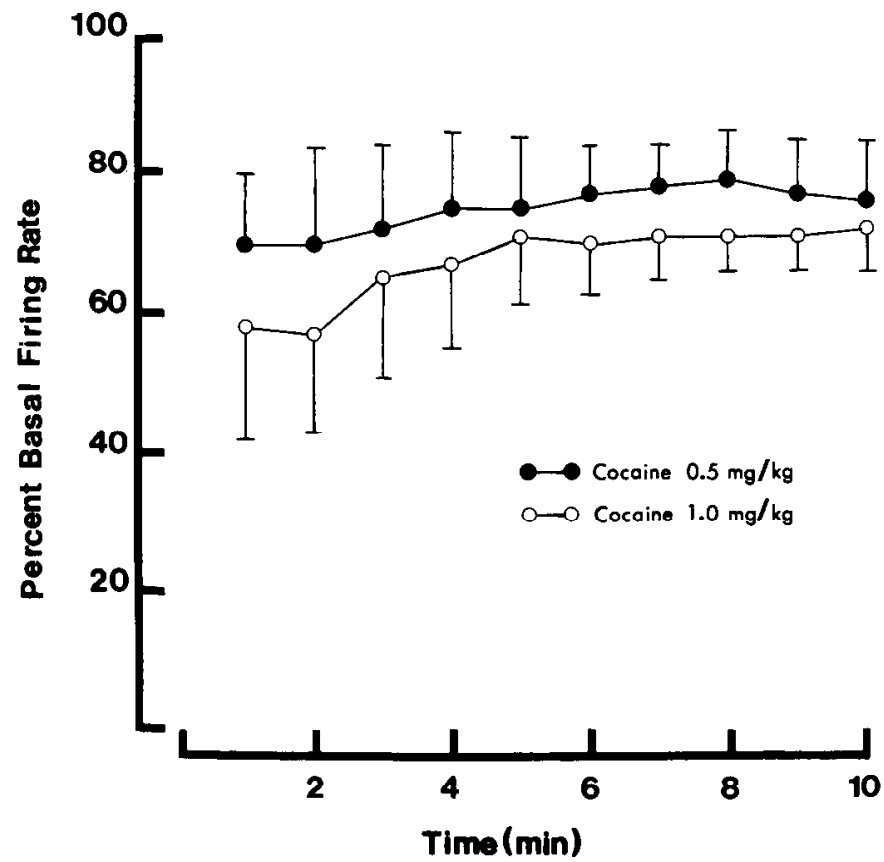

Figure 2. Time course for the inhibitory effect of intravenous cocaine on the firing of A10 DA neurons in the rat VTA. Cocaine was administered as a single bolus injection of either 0.5 or $1.0 \mathrm{mg} / \mathrm{kg}$, and the activity of the cell was monitored for recovery for at least $10 \mathrm{~min}$. Data points represent means, bars represent SEM ( $n=8$ /group).

held for longer than $10 \mathrm{~min}$; only 2 cells returned to within $10 \%$ of their basal rate within the first $10 \mathrm{~min}$, whereas one other cell returned to within $10 \%$ of its basal rate following $14 \mathrm{~min}$. At the lower dose of $0.5 \mathrm{mg} / \mathrm{kg}, 7$ out of the 8 cells studied were inhibited and 1 cell was excited. Examples of the responses of
A10 DA neurons to single injections of $0.5 \mathrm{mg} / \mathrm{kg}$ of cocaine are shown in Figure $3 A, B$. At the $1.0 \mathrm{mg} / \mathrm{kg}$ dose, 6 cells showed inhibition, whereas 1 cell showed an increase in firing rate for $6 \mathrm{~min}$, which was followed by a decrease to approximately $50 \%$ of the basal firing rate (Fig. $3 D$ ), and 1 cell showed virtually no response to cocaine. This cell showed only slight $(20 \%)$ inhibition for the first $2 \mathrm{~min}$, then stabilized at $97 \%$ basal firing rate. Figure $3 C$ shows an example of the typical response to a single injection of $1.0 \mathrm{mg} / \mathrm{kg}$, i.v., of cocaine.

\section{Intravenous drug comparison studies}

Because cocaine inhibits the reuptake of NE, DA, and 5-HT and exerts local anesthetic effects, a series of comparative experiments was conducted to determine the mechanism(s) responsible for the effects of intravenous cocaine on A10 DA neurons. The selective 5-HT uptake inhibitor fluoxetine (Wong et al., 1974) was used to test a serotonergic involvement, while desmethylimipramine (DMI), a relatively selective NE uptake inhibitor (Koe, 1976), was used to test NE involvement. The local anesthetic procaine was employed to determine whether the suppression of A10 DA activity was a result of local anesthetic actions of cocaine. To ascertain further the role of dopaminergic reuptake blockade, we compared the effects of nomifensine, a DA and NE reuptake inhibitor (Van der Zee et al., 1980; Heikkila and Manzino, 1984), and GBR-12909, a selective DA uptake inhibitor (Van der Zee et al., 1980; Heikkila and Manzino, 1984). In addition, norcocaine, the $\mathrm{N}$-demethylated, active metabolite of cocaine (Williams et al., 1977; Spealman and Kelleher, 1981; Bagchi and Rielly, 1983) was tested to determine its CNS activity and potency relative to cocaine.

The comparative effects of intravenous administration of these various compounds on A10 DA neuronal activity are presented in Figure 1, in which the percentage of basal firing rate is plotted as a function of the cumulative dose of drug from 0.1 to 3.1
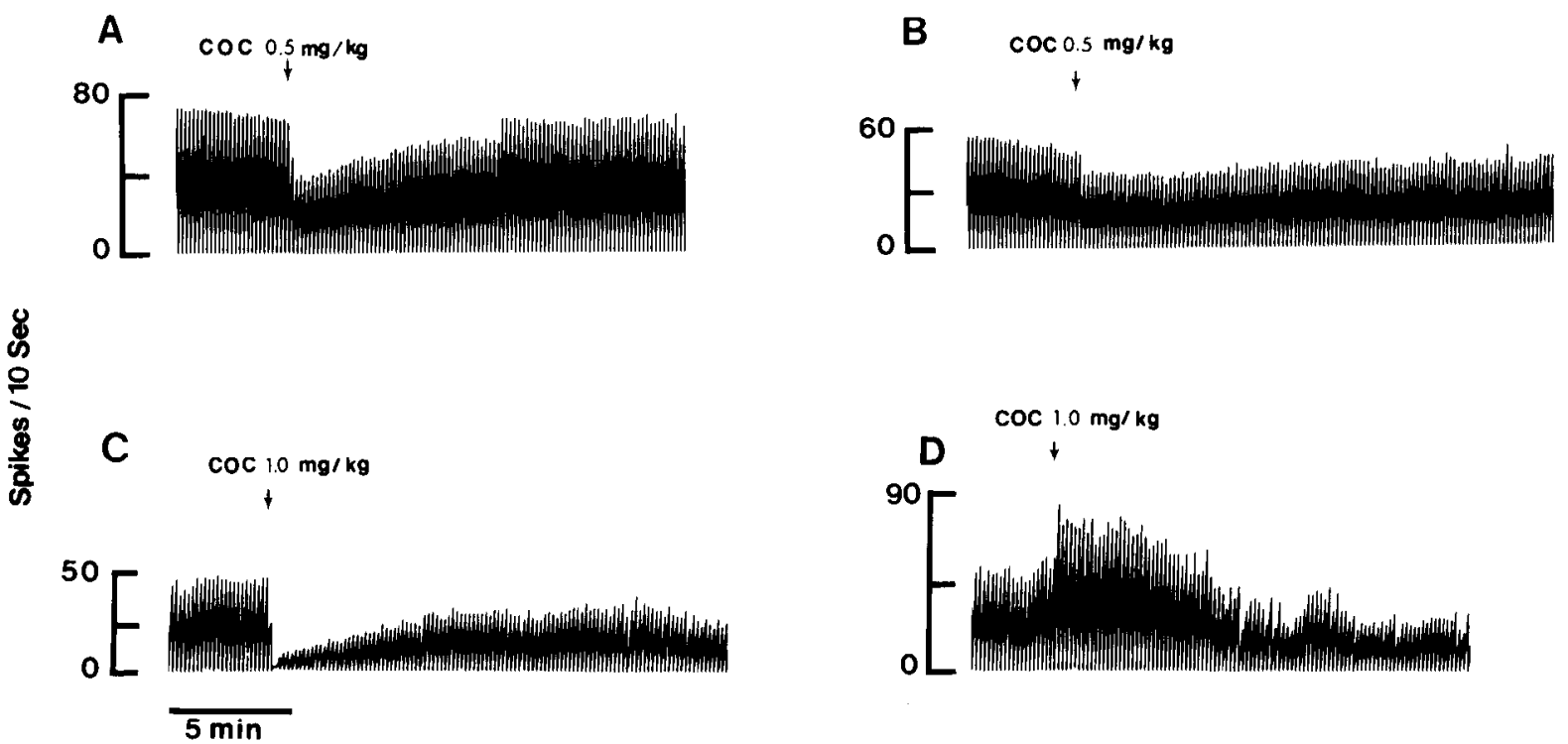

Figure 3. Examples of the effects of intravenous cocaine (injected at arrows) on the firing of A10 DA neurons in the rat VTA. $A, B$, Cumulative rate histograms illustrating the effects of bolus injections of $0.5 \mathrm{mg} / \mathrm{kg}$. Note that the cell in $A$ recovered to near basal levels within 8 min, whereas the cell in $B$ was less inhibited by cocaine, but failed to recover within the $19 \mathrm{~min}$ recording period. $C, D$, Cumulative rate histograms illustrating the effects of bolus injections of $1.0 \mathrm{mg} / \mathrm{kg}$. The cell in $C$ was inhibited completely immediately following the injection, but began to recover slowly, reaching approximately $60 \%$ basal firing rate within the $18 \mathrm{~min}$ recording period. The cell in $D$ exhibited a biphasic excitation/inhibition following the cocaine injection, first accelerating to $152 \%$ of its basal rate and then slowing to $50 \%$ of basal activity, the rate that was maintained throughout the remainder of the recording period. 


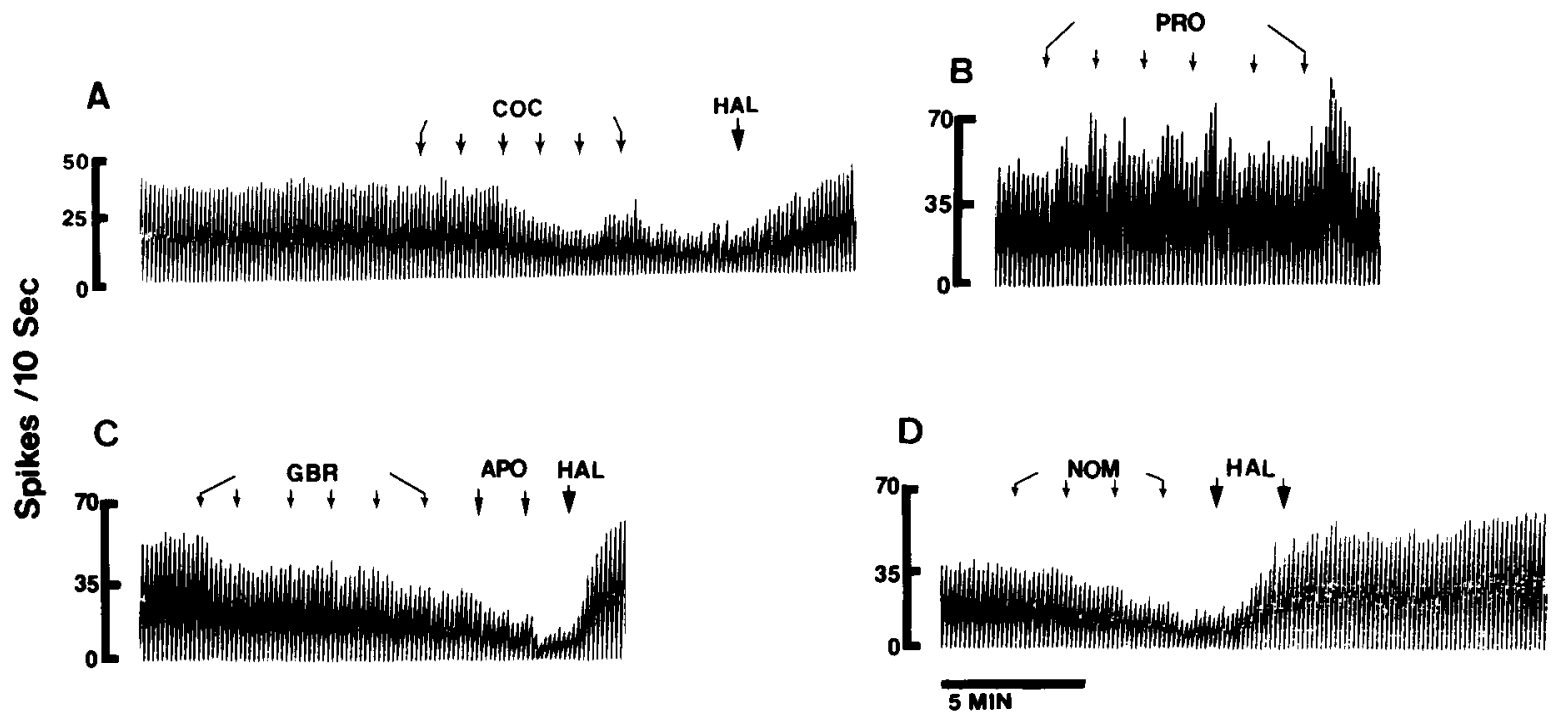

Figure 4. Cumulative rate histograms showing examples of the effects of cumulative intravenous doses of cocaine, procaine, GBR-12909, and nomifensine on the firing of A10 DA neurons within the rat VTA. $A$, Typical partial inhibitory effect of cocaine $(C O C ; 0.1,0.2,0.4 \mathrm{mg} / \mathrm{kg}$, etc., at arrows) on an antidromically identified mesoaccumbens A10 DA neuron, and the reversal of that effect by the DA antagonist haloperidol ( $H A L$; $0.2 \mathrm{mg} / \mathrm{kg}) . B$, Slight transient increases in firing caused by each injection of procaine $(P R O ; 0.1-3.2 \mathrm{mg} / \mathrm{kg})$. C, Partial inhibitory effect of GBR$12909(G B R ; 0.1-3.2 \mathrm{mg} / \mathrm{kg})$, the subsequent further inhibition caused by apomorphine $(A P O ; 0.001$ and $0.002 \mathrm{mg} / \mathrm{kg})$, and the reversal of inhibition by haloperidol $(H A L ; 0.2 \mathrm{mg} / \mathrm{kg}) . D$, Typical partial inhibition caused by nomifensine $(0.1-0.8 \mathrm{mg} / \mathrm{kg})$ and the reversal by haloperidol $(H A L ; 0.1$ and $0.2 \mathrm{mg} / \mathrm{kg}$ ).

$\mathrm{mg} / \mathrm{kg}$. GBR-12909, cocaine, nomifensine, and norcocaine all caused significant $(F(4,100)=71.8, p<0.001)$ dose-dependent, partial inhibitions of the activity of A10 DA neurons. Significant differences were obtained between the inhibition curves for GBR12909 , nomifensine, cocaine, and norcocaine $(F(3,25)=5.5$, $p<0.01)$. Post hoc tests indicated that the potencies of nomifensine and cocaine did not differ from each other, but were greater than that of GBR-12909, whose potency was greater than that of norcocaine $(p<0.01)$. Thus, the rank order of potency for these compounds was nomifensine $\geq$ cocaine $>$ GBR-12909 > norcocaine, with corresponding $\mathrm{ID}_{50}$ values of $1.5 \pm 0.4,2.2 \pm 0.3,8.2 \pm 1.6$, and $>10$ (mean $\pm \mathrm{SEM}$ ), as estimated by log-probit analysis. ANCOVA revealed that the difference between the $\mathrm{ID}_{50}$ values for the various treatment groups could not be accounted for $(F(3,24)=5.2, p<0.01)$ by the difference in the mean basal firing rates of the neurons sampled (see White and Wang, 1984a). Haloperidol reversed the effects of each of these compounds on A10 DA neurons. Examples of the effects of intravenous cocaine, GBR-12909, and nomifensine are shown in Figure $4 A, C, D$.

In contrast to these agents, fluoxetine, DMI, and procaine failed to inhibit the firing of A10 DA neurons. In fact, procaine caused a transient increase in firing rates (Fig. $4 B$ ); even at doses of $\geq 12 \mathrm{mg} / \mathrm{kg}$, procaine never caused an inhibition of A10 DA neuronal activity. Figures 1 and 4 also show that, even at high doses, the various drugs tested seldom causcd complete suppression of A10 DA activity. The maximum effect was typically 40$75 \%$ of the basal firing rate. Subsequent administration of directacting DA agonists such as apomorphine (APO; $1-10 \mu \mathrm{g} / \mathrm{kg}$ ) further inhibited the firing of neurons that had been partially inhibited by these indirect agonists (Fig. $4 C$ ).

\section{Effects of reserpine on cocaine-induced inhibition}

To determine whether the effects of cocaine on A10 DA neurons were dependent on endogenous DA, rats were pretreated with reserpine, which causes a depletion of catecholamines (and serotonin) by interfering with vesicular storage (Carlsson et al., 1957). As is clearly illustrated in Figure 5, the ability of cocaine to inhibit A10 DA neurons was significantly $(F(1,10)=5.1, p<$ 0.05 ) attenuated in rats that had been pretreated with reserpine, as compared to vehicle-pretreated rats. Of the 9 cells recorded after reserpine pretreatment, 4 cells showed an initial increase

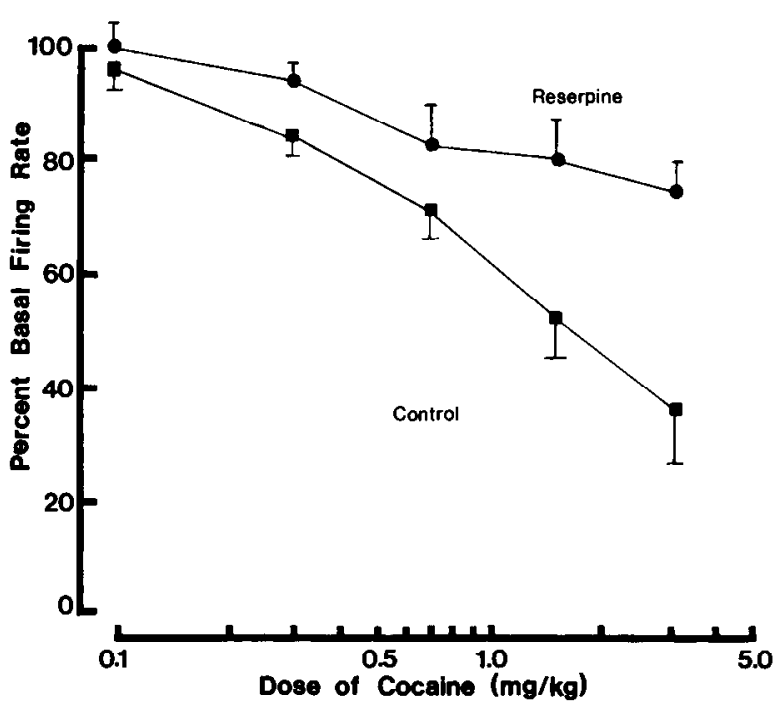

Figure 5. Ability of reserpine pretreatment to attenuate the inhibitory effects of intravenous cocaine on A10 DA neurons in the rat VTA. Reserpine-treated rats $(n=9)$ received $5.0 \mathrm{mg} / \mathrm{kg}$, i.p., 18-24 hr prior to recording, whereas control rats $(n=9)$ received vehicle injections. Each rat received cumulative injections of cocaine such that each dose doubled the previously administered dose (i.e., $0.1,0.2,0.4 \mathrm{mg} / \mathrm{kg}$, etc.). Data points represent means, bars represent SEM. The data points for the reserpine-treated group are all significantly different from those of the control groups except at the first dose of cocaine $(p<0.05)$. 


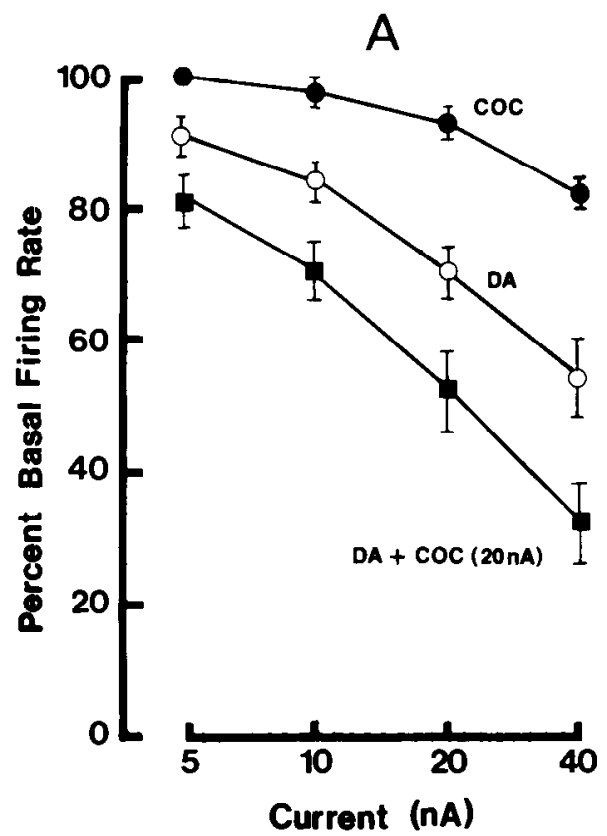

B

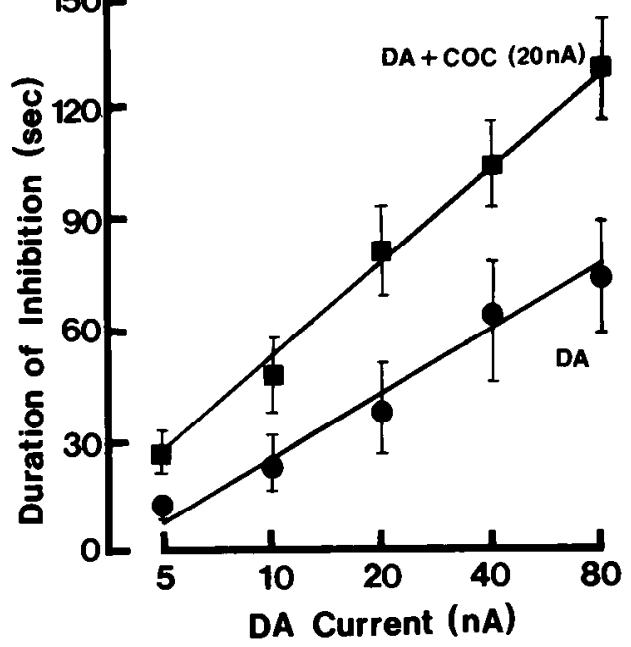

Figure 6. Effects of iontophoretically administered cocaine $(0.01 \mathrm{~m})$ on the activity of A10 DA neurons within the rat VTA. $A$, Current-response curves for the inhibitory effects of cocaine $(C O C)$. DA $(0.01 \mathrm{M})$ and DA + COC $(20 \mathrm{nA})$. Filled circles indicate the weak inhibitory effects of increasing iontophoretic currents applied through the cocaine (COC) barrel ( $n=12$ cells in 7 rats). Although higher currents often further inhibited firing, this effect was usually accompanied by a decreased amplitude of the waveform, suggesting local anesthetic effects (see text). Open circles indicate the inhibitory effects of DA alone ( $n=10$ cells in 5 rats), whereas filled squares indicate the effects of coadministration of DA and a 20 $\mathrm{nA}$ current of COC on those same 10 cells. For the coadministration data points, the inhibition produced by COC alone was determined first and subtracted from the amount of inhibition produced by the coadministration of COC and DA. COC significantly increased the inhibitory effect of DA at all currents of DA $(p<0.01), B$, COC also significantly increased the duration of the inhibitory effect of DA on those same 10 cells shown in $A$. The $80 \mathrm{nA}$ current includes only 4 of the 10 cells. For these determinations, the duration of inhibition was defined as the time required for the cell to recover to $\geq 85 \%$ of its basal rate for 3 consecutive $10 \mathrm{sec}$ epochs. Data points represent means, bars indicate SEM.

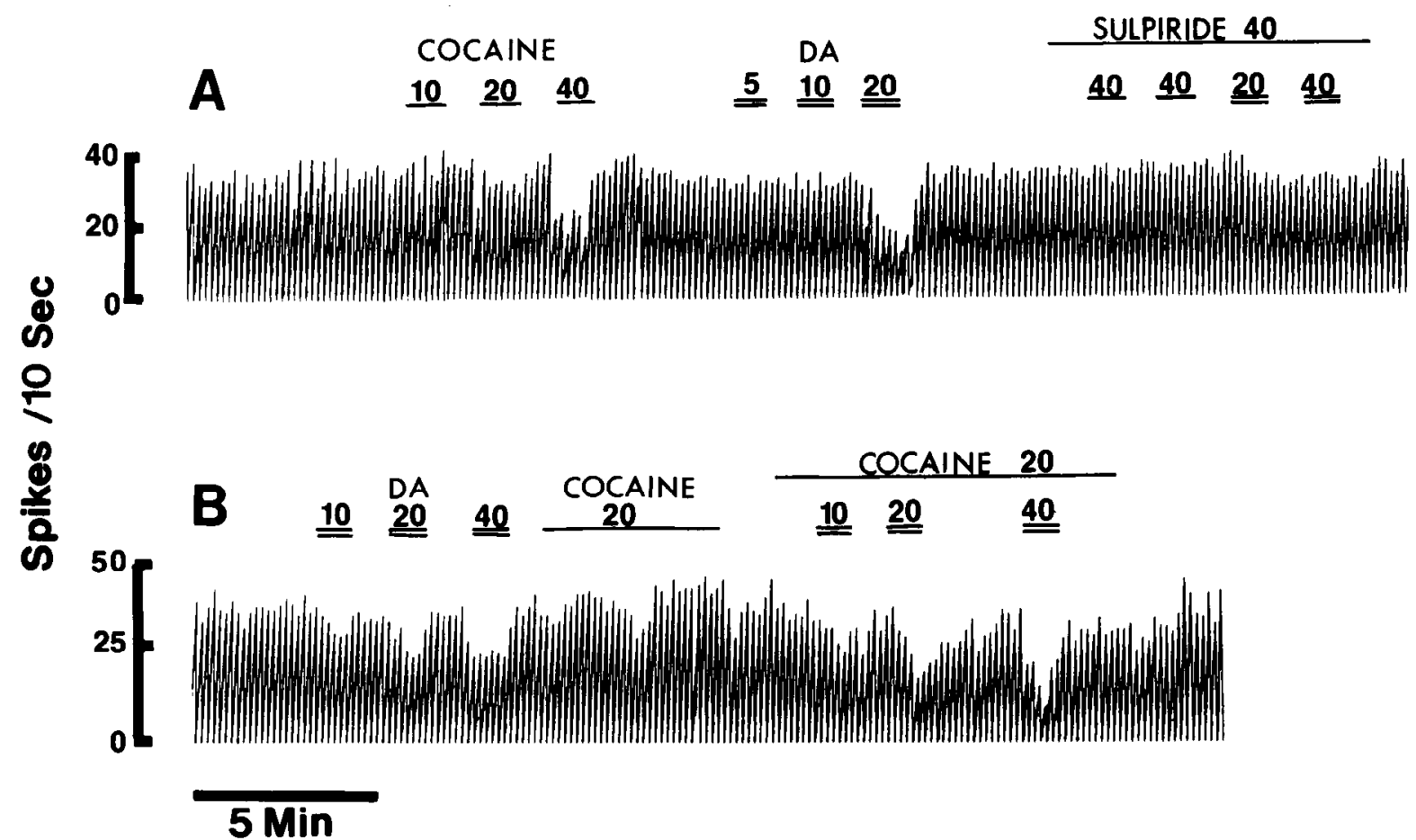

Figure 7. Cumulative rate histograms illustrating the effects of iontophoretic cocaine and DA on A10 DA neurons within the rat VTA. $A$, The inhibitory effects of cocaine and DA on this A 10 DA neuron were almost completely blocked by coadministration of the D-2 DA receptor antagonist, L-sulpiride. $B$, Cocaine $(20 \mathrm{nA})$ only slightly inhibited the firing of this neuron, but increased both the amount and the duration of inhibition caused by DA. Lines and numbers represent the duration of iontophoretic current and the amount of current in nanoamperes. 
C:
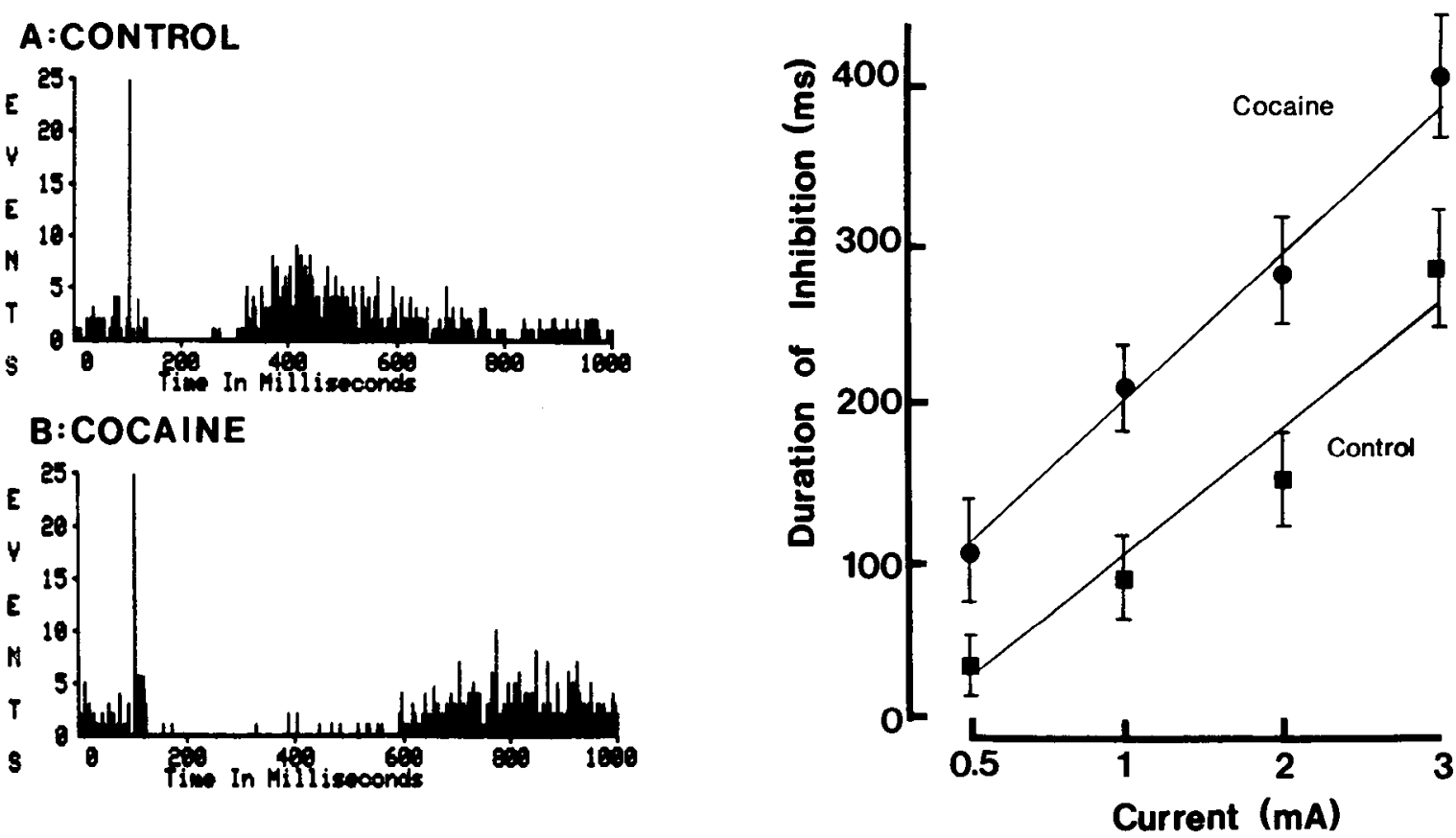

Figure 8. The ability of iontophoretically administered cocaine $(0.01 \mathrm{M}, 20 \mathrm{nA})$ to enhance the inhibition of firing of antidromically identified mesoaccumbens A10 DA neurons caused by electrical stimulation of the nucleus accumbens (NAc). $A$, Peristimulus time histogram (PSTH) illustrating the inhibition of firing of a mesoaccumbens DA neuron during NAc stimulation ( $2.0 \mathrm{~mA}$ for $0.5 \mathrm{msec})$. B, PSTH obtained from the same cell shown in $A$ during iontophoretic administration of cocaine $(20 \mathrm{nA})$. Each PSTH was obtained from 25 sweeps initiated 100 msec before the onset of the electrical stimulation (bin width, $4 \mathrm{msec}$ ). Shock artifacts are evident at $100 \mathrm{msec}$. $C$, Averaged data obtained from 6 cells tested in the manner shown in $A$ and $B$. For these cells, the onset of the inhibitory period was defined as the point at which 3 consecutive bins accumulated 0 events and the termination of the inhibition was defined as that point at which at least 2 consecutive bins accumulatcd at lcast 2 events. For each cell, 25 sweeps were collected at each intensity with a 1 min recovery period between each intensity. Following a 3 min recovery period, cocaine iontophoresis was initiated $1 \mathrm{~min}$ prior to beginning a second current-response curve and was maintained throughout the duration of the second determination. The difference between the control and cocaine conditions was significant at all current intensities $(p<0.01)$.

in firing rate, followed by slight inhibition. Two cells in the vehicle group were excited by cocaine administration. None of the cells in the reserpine group were inhibited to less than $57 \%$ of the basal firing rate.

\section{Microiontophoresis}

To test directly the possibility that cocaine inhibited mesoaccumbens DA neurons by blocking dendritic DA reuptake and potentiating the stimulation of autoreceptors by DA, cocaine was administered directly onto DA neurons via microiontophoresis. Surprisingly, cocaine produced only a $20 \%$ inhibition of firing of antidromically identified mesoaccumbens DA neurons at the currents tested (5-40 nA). However, constant application of a $20 \mathrm{nA}$ current through the cocaine barrel significantly $(F(1,18)=4.7, p<0.05)$ increased the inhibitory potency of iontophoretic DA (Fig. 6A). When the duration of DA-induced inhibition was measured as the length of time (number of $10 \mathrm{sec}$ epochs) before the cell regained its basal rate, cocaine was also observed to increase significantly $(F(1,10)=34.8, p<$ 0.001 ) the duration of the inhibitory period produced by increasing iontophoretic currents of DA (Fig. 6B). Moreover, the significant $(F(4,40)=8.81, p<0.001)$ interaction between current and groups indicated that the potentiating effects of cocaine were enhanced as the amount of current applied to the DA barrel was increased. Examples of these effects are shown in Figure 7.

When cocaine was ejected at currents $\geq 40 \mathrm{nA}$, apparent local anesthetic effects were sometimes observed, i.e., diminished spike amplitude and flattened waveform. However, it seems unlikely

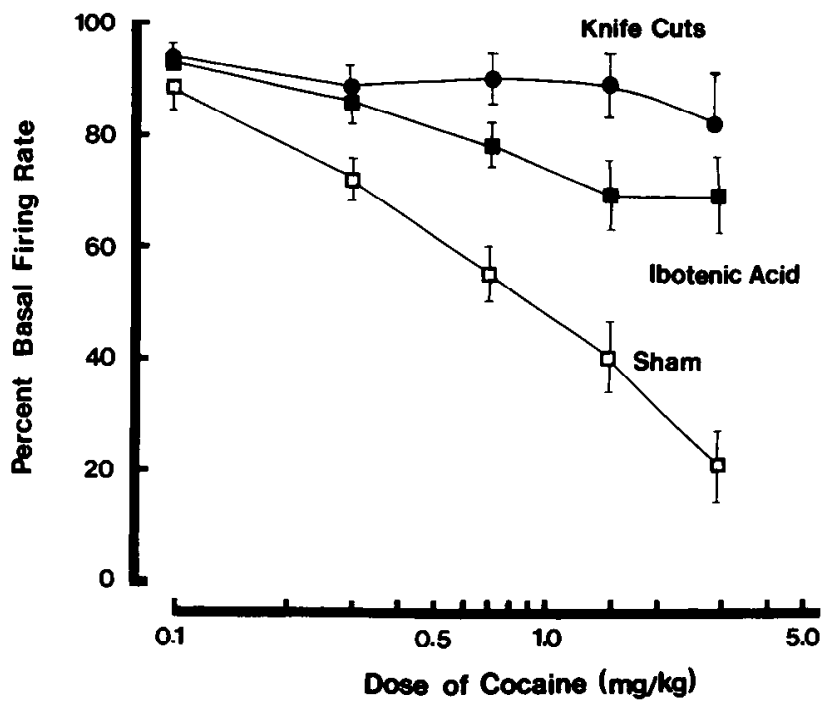

Figure 9. Effects of removing possible forebrain feedback pathways on the inhibitory potency of cocaine on A10 DA neurons within the rat VTA. Both ibotenic acid-induced lesions of the NAc 1 week prior to recording $(n=8)$ and acute hemitransections of the brain rostral to the VTA $(n=8)$ significantly attenuated the inhibitory effects of intravenous cocaine on A10 DA neurons as compared to a sham-operated control group $(n=9)$. Cocaine was injected on a cumulative dose basis such that each dose doubled the previously administered dose $(0.1,0.2,0.4$ $\mathrm{mg} / \mathrm{kg}$, etc.). Data points represent means, bars represent SEM. The data points for both of the lesion groups were significantly different from those of the sham group except at the $0.1 \mathrm{mg} / \mathrm{kg}$ dose of cocaine $(p<$ 0.01 ). 


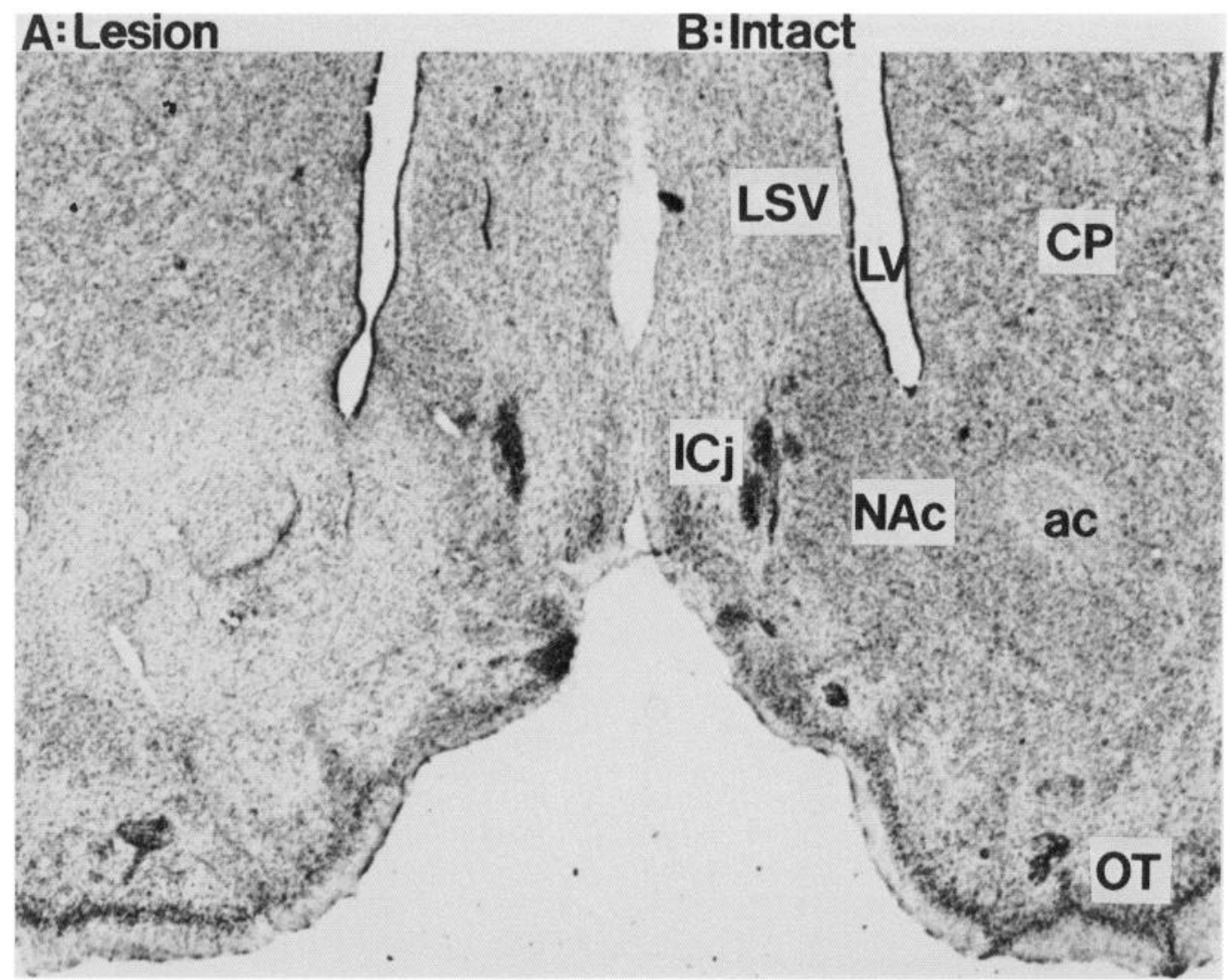

Figure 10. Photomicrograph illustrating unilateral $(A)$ ibotenic acid-induced lesions of the nucleus accumbens $(N A C)$ as compared to the intact, contralateral NAc $(B)$. For this lesion, there was near-total elimination of cell bodies within the NAc, with minimal damage to the caudatoputamen $(C P)$, ventral lateral septal nucleus $(L S V)$ or olfactory tubercle $(O T)$. Other abbreviations: $a c$, anterior commissure, $I C j$, Island of Calleja; $L V$, lateral ventricle.

that local anesthetic effects were involved in the effects of cocaine ejected at lower currents, because such effects were completely blocked by simultaneous administration of the D-2 DA receptor antagonist (L)-sulpiride (Fig. $7 A$ ).

\section{Electrical stimulation of the nucleus accumbens}

As a means of determining whether cocaine could potentiate the effects of endogenously released DA on DA autoreceptors, electrical stimulation of the NAc was used to antidromically stimulate dendritic DA release (Wang, 1981b). Figure $8 A$ shows a PSTH that illustrates the inhibition of an antidromically identified mesoaccumbens DA neuron following electrical stimulation of the NAc $(2.0 \mathrm{~mA}$ for $0.5 \mathrm{msec})$. During iontophoresis of cocaine $(20 \mathrm{nA})$, the duration of inhibition of this neuron was considerably prolonged (Fig. $8 B$ ). Figure $8 C$ shows the averaged data obtained from 7 mesoaccumbens DA neurons. The duration of inhibition caused by NAc stimulation was significantly $(F(1,12)=30.6, p<0.001)$ longer during cocaine iontophoresis. The ANOVA also revealed that duration of inhibition produced by the stimulation was significantly $(F(3,36)=$ $42.3, p<0.001)$ related to the current intensity and that the degree of potentiation produced by cocaine increased with increasing currents, i.e., there was a significant interaction $(F(3,36)=12.6, p<0.001)$.

\section{Removal of forebrain feedback pathways}

To determine the role of possible NAc-VTA inhibitory feedback pathways in the effects of cocaine on A10 DA neurons, both ibotenic acid lesions of cells within the NAc and acute hemitransections were used to eliminate this possible source of afferent control. In both groups of rats, the ability of intravenous cocaine to inhibit the activity of A10 DA neurons was significantly reduced as compared to that in sham-operated animals $(F(2,20)=26.1, p<0.001)$ (Fig. 9); this effect was not due to differences in basal firing rates between the various groups $(F(2,19)=24.3, p<0.001)$. The maximal inhibitory effect of cocaine was only $25 \%$ in the NAc lesion group and only $18 \%$ in the hemitransection group. Similar doses in the sham-operated animals resulted in nearly a $70 \%$ inhibition of neuronal activity.

For 5 of the 8 ibotenic acid-lesioned rats, the extent of the lesion was primarily circumscribed within the NAc proper, with slight damage to the dorsal olfactory tubercle or to the most ventral aspects of the caudate nucleus (see Fig. 10, for example). Two rats had more extensive damage, which encroached upon the ventral lateral striatum and lateral septal nucleus. One rat had significant additional damage to the olfactory tubercle.

\section{Discussion}

These experiments have demonstrated that systemic (i.v.) administration of cocaine caused a dose-dependent, partial inhibition of the firing of antidromically identified mesoaccumbens A10 DA neurons. For those cells tested for recovery, firing rates usually returned to within $80 \%$ of basal levels within 20 min following cocaine administration, a finding that is in agreement with the well-known short duration of the psychoactive 
effects of this drug (Fischman et al., 1983). The inhibitory effects of cocaine on A10 DA neurons were slower in onset and longer in duration that the pressor effects of cocaine, as observed in rats under highly similar conditions (Pitts and Marwah, 1987), indicating that the cardiovascular effects of cocaine are probably not responsible for the observed neuronal inhibition.

Although cocaine is known to inhibit the reuptake of DA, NE, and 5-HT (Ross and Renyi, 1967a, b; Snyder and Coyle, 1969; Heikkila et al., 1975), the inhibitory effects of intravenous cocaine on A10 DA cells appeared to be dependent on increased stimulation of DA receptors, since they were reversed by the DA antagonist haloperidol, but not by the $\alpha-1$ antagonist prazosin or the $\alpha$-2 antagonist piperoxane. In addition, neither the relatively selective NE uptake inhibitor DMI (Koe, 1976) nor the selective 5-HT uptake inhibitor fluoxetine (Wong et al., 1974) suppressed the activity of A 10 DA cells. In contrast, the catecholamine uptake inhibitor nomifensine (Williams et al., 1977) and the highly selective DA uptake blocker GBR-12909 (Van der Zee et al., 1980; Heikkila and Manzino, 1984) inhibited A10 DA neurons in a dose-dependent, partial, haloperidol-reversible manner similar to that of cocaine. Although cocaine exerts local anesthetic actions (Carney, 1955), such a mechanism did not appcar to bc involved in the effects of intravenous cocaine on A10 DA cells, since the local anesthetic procaine, which does not block DA uptake (Ritchie and Greene, 1980), failed to inhibit A10 cells even at high doses. In fact, procaine caused a transient increase in the activity of most A10 DA cells tested. Moreover, intravenous cocaine never caused decreases in the spike amplitude of DA neurons, an effect typically associated with a local anesthetic action (see below).

Additional evidence for an indirect action of cocaine on A10 DA neurons via alterations in DA reuptake was obtained by demonstrating that pretreatment with reserpine, which depletes vesicular stores of DA (Carlsson et al., 1957), significantly reduced the inhibitory effects of cocaine. The fact that some inhibition still occurred in reserpinized rats may be explained by the release of newly synthesized (cytoplasmic) DA and/or incomplete depletion of vesicular stores. Moreover, DA may be stored in vesicles only within proximal dendrites (Groves and Linder, 1983), since there is little evidence for storage vesicles within distal DA dendrites (Wassef et al., 1981). Therefore, both vesicular and nonvesicular processes may contribute to the release of dendritic DA (Chéramy et al., 1981).

The series of microiontophoretic experiments revealed more direct evidence that cocaine-induced suppression of A10 DA neurons results from blockade of the DA reuptake mechanism. Microiontophoretic administration of cocaine onto A10 DA cells in the VTA caused only weak (15-20\%) suppression of the activity of A10 DA neurons even at relatively high ejection currents (40 nA). At higher currents, a decrease in spike amplitude, concomitant with a slowing of firing, was observed. Similar effects were obtained with iontophoretic administration of procaine. These effects are thought to be indicative of local anesthetic actions (Taylor, 1959; Nicoll et al., 1977). However, the rate suppression observed at lower cocaine currents appeared to be DA-dependent, since it was blocked by coiontophoresis of the selective D-2 DA receptor antagonist L-sulpiride (Creese et al., 1983; White and Wang, 1984b). More important, low currents of cocaine, which alone produced little rate suppression, significantly increased and prolonged the inhibition produced by iontophoretic ejection of DA.

Cocaine also potentiated the effects of endogenously released
DA on mesoaccumbens A10 DA cells. As previously reported (Wolfe et al., 1978; German et al., 1980; Yim and Mogenson, 1980; Wang, 1981b), electrical stimulation of the NAc caused a poststimulus inhibition of A 10 DA activity due to DA released upon antidromic invasion of the DA neurons (Korf et al., 1976; Wang, 1981b). The duration of the inhibition was directly related to the intensity of the current, presumably becausc higher currents spread through the NAc, recruiting more DA fibers and thereby increasing the number of DA neurons releasing dendritic DA in the VTA. Low iontophoretic currents of cocaine $(20 \mathrm{nA})$ caused a significant prolongation of this stimulationinduced inhibition, suggesting that cocaine reduces DA reuptake along the somatodendritic extent of A10 DA neurons, thereby increasing extracellular levels of DA and prolonging its effects at somatodendritic impulse-regulating autoreceptors.

Taken together, the findings obtained from the intravenous and iontophoretic experiments indicate that systemically administered cocaine inhibits the activity of mesoaccumbens DA neurons by blocking the reuptake of DA, thereby enhancing its effects on DA receptors. Unlike most DA agonists, which completely suppress A10 DA neuronal activity (Bunney et al., 1973; Wang, 1981a, c; White and Wang, 1984b), the maximal effect was typically only $50-70 \%$ inhibition, suggesting that, while cocaine increases concentrations of DA and thereby enhances DA-induced inhibition of A10 DA neurons at the somatodendritic autoreceptor, the mechanism of reuptake blockade in itself may be insufficient, i.e., does not raise extracellular somatodendritic DA levels enough to halt the firing of A10 DA neurons completely.

It is also interesting to note that, whereas intravenous administration of cocaine usually resulted in a $50-70 \%$ inhibition of mesoaccumbens DA neuronal activity, iontophoretic administration in the VTA resulted in only a very weak (10-20\%) suppression of firing. Although this discrepancy might be explained by ineffective ejection of cocaine from the pipettes, this seems unlikely, since marked inhibition of NAc neurons has been observed under identical conditions (White, 1986b; White et al., 1987). Contributions to this difference are also likely to result from the failure of iontophoretic cocaine to reach distal dendrites, where additional uptake sites may be located and where extensive electrical coupling might exist (Grace and Bunney, 1983b). However, preliminary recordings obtained from in vitro VTA slice preparations indicate that, when superfused over the slice, cocaine only partially inhibited most A10 DA cells (Brodie and Dunwiddie, 1986; F. J. White, unpublished observations). In view of these considerations and preliminary results indicating that iontophoretic administration of cocaine onto NAc neurons resulted in a significantly greater inhibition than that observed on A10 DA neurons (White, 1986b; White et al., 1987), a situation unlike that with other DA agonists (White and Wang, 1986), we suspect that the difference between the potencies of iontophoretic and intravenous cocaine on A10 DA neurons may have been due to the additional involvement of a NAc-VTA feedback pathway in the inhibitory effects of intravenous cocaine.

Although considerably less extensive than the striatonigral pathway, a NAc-VTA GABAergic (inhibitory) feedback pathway has been indicated by several anatomical (Nauta et al., 1978; Phillipson, 1979), biochemical (Waddington and Cross, 1978; Walaas and Fonnum, 1980) and electrophysiological (Wolfe et al., 1978; German et al., 1980; Yim and Mogenson, 1980; Whitc and Wang, 1983a) studics. For example, the in- 
hibitory effects of electrical stimulation of the NAc on some A10 DA neurons are enhanced by iontophoretic application of the GABA reuptake inhibitor nipecotic acid into the VTA, and blocked by similar administration of the GABA antagonist picrotoxin (Wolfe et al., 1978; Yim and Mogenson, 1980). In addition, lesions of the NAc decrease levels of the GABA-synthesizing enzyme glutamic acid decarboxylase (GAD) in at least some portions of the VTA (Waddington and Cross, 1978; Walaas and Fonnum, 1980).

Our experiments support a role for NAc-VTA pathways in the effects of cocaine on A10 DA neurons since both ibotenic acid lesions of the NAc and acute hemitransections significantly attenuated the suppression of firing produced by intravenous cocaine. Thus, by blocking the DA uptake mechanism at DA nerve terminals within the NAc, cocaine increased synaptic concentrations of DA, thereby inhibiting NAc neurons (White, 1986b; White et al., 1987) and activating feedback mechanisms to the VTA. If this pathway is GABAergic, then it is necessary to postulate that, as in the striatonigral feedback pathway (Grace and Bunney, 1985), the primary target of such afferents would be inhibitory interneurons within the VTA. Previous pharmacological evidence suggests the existence of such interneurons, probably themselves GABAergic, within the VTA (Waszczak and Walters, 1980; Gysling and Wang, 1983; O'Brien and White, 1987). If the presumed GABAergic neurons terminate both on interneurons and on the A10 DA neurons within the striatonigral pathway, as has been suggested (Grace and Bunney, 1985), then the net effects of cocaine would be determined by the relative degree of innervation of the A10 DA cell by the direct and indirect pathways. Such an arrangement could help to explain the occasional A10 DA cell that is excited by intravenous cocaine, since excitation (disinhibition) would be predicted if certain A10 DA cells received primarily direct NAc-VTA GABAergic inputs.

The present findings represent the first report of an involvement of NAc-VTA feedback pathways in the effects of a DA agonist on A10 DA cells. Several investigators have postulated that mesolimbic and nigrostriatal DA systems differ in the relative degree of autoreceptor rcgulation (predominant on mcsolimbic neurons) versus long-loop feedback regulation (predominant on nigrostriatal neurons) of impulse flow (Wang, $198 \mathrm{lc}$; Andén et al., 1983; Chiodo and Bunney, 1984). For example, it has been shown that the inhibitory effects of the DA-releasing agent $d$-amphetamine on A9 DA neurons are diminished by lesions placed along the striatonigral pathway (Bunney and Aghajanian, 1976), whereas such effects on A10 DA neurons are unaffected either by lesions of the NAc or by hemitransections (Wang, 1981c). Our findings are not necessarily inconsistent with this view. In fact, we have recently replicated the previous failure of ibotenic acid lesions to alter the inhibitory effects of $d$-amphetamine on A10 DA cells (White et al., 1987). We propose that the difference between amphetamine and cocaine in this regard relates to differences in their mode of action, i.e., enhancement of dendritic DA release by $d$-amphetamine produces significantly greater extracellular concentrations of DA within the VTA than does blockade of DA reuptake by cocaine. Given that the inhibitory effects of cocaine are much greater postsynaptically (within the NAc) than at the somatodendritic autoreceptor on A10 DA cells (White, 1986b; White et al., 1987), it is tempting to speculate that the NAc-VTA feedback pathway is used only (i.e., is not redundant) when autoreceptor-induced inhibition of A 10 DA neurons is insufficient to compensate for enhanced activation of postsynaptic DA receptors.

The present findings have several potentially important implications for the hypothesis that enhanced activity within the mesoaccumbens DA system may be responsible, at least in part, for the rewarding effects of cocaine and other drugs of abuse (Wise, 1980, 1984; White et al., 1987). First, the decrease in A10 unit activity produced by DA agonists is entirely consistent with this hypothesis, because such decreases represent a compensatory decrease in impulse flow as a consequence of enhanced DA neurotransmission within the NAc. Other classes of drugs that possess reinforcing properties increase A10 unit activity via non-dopaminergic mechanisms. These include opioids (Gysling and Wang, 1983; Matthews and German, 1984), ethanol (Gessa et al., 1985; see also Imperato and Di Chiara, 1986), benzodiazepines (O'Brien and White, 1987), and nicotine (Yoon et al., 1986). The ability of these drugs to increase A10 unit firing results in enhanced mesoaccumbens DA transmission, whereas the decrease in A10 DA neuronal impulse flow caused by DA agonists results from enhanced activation of NAc DA receptors, i.e., increased DA transmission. It is possible that the drugs that stimulate DA transmission by working at nondopaminergic receptors (opioid, benzodiazepine/GABA) in some way "override" autoreceptor control, perhaps because increased DA impulse flow may be inversely related to dendritic DA release (Chéramy et al., 1981).

Since the various classes of compounds possessing rewarding properties affect A10 DA cells differently, it will not be possible to predict the potential abuse liability of drugs solely on the basis of their effects on A10 DA cells. Clearly, such predictions will require an analysis of the net effects of each compound on in vivo DA activity within the mesoaccumbens pathway. In this respect, it is interesting to note that all of the drugs that inhibited A10 DA cell firing in the present study appear to possess reinforcing efficacy. In addition to cocaine, its $\mathrm{N}$-demethylated derivative norcocaine is readily self-administered by laboratory animals (Risner and Jones, 1980; Spealman and Kelleher, 1981). Although self-administration experiments have not been reported for nomifensine and GBR-12909, both of these drugs produce a conditioned place preference (Martin-Iverson et al., 1985; R. Brooderson, S. R. Wachtel, and F. J. White, unpublished observations), an effect thought to reflect reinforcing efficacy (Mucha et al., 1982). Given that these drugs exert effects on A10 DA cells that are similar to those of cocaine, it is likely that they also act via a combination of autoreceptor and feedback mechanisms.

A final implication of these experiments relates to how the observed effects of cocaine on mesoaccumbens DA cells differ from those exerted by other DA agonists. Because D-2 DA autoreceptors within the mesoaccumbens pathway are 3-10 times more responsive to DA and DA agonists than are postsynaptic D-2 receptors within the NAc (White and Wang, 1986), most DA agonists not only stimulate DA receptors in the NAc but also activate compensatory autoreceptor mechanisms that diminish DA impulse flow, synthesis, and release (Carlsson, 1975; Roth, 1979). In contrast, by blocking the reuptake of both DA and 5-HT, cocaine potently suppresses the firing of a subpopulation of NAc neurons that is inhibited by both of these amines (White, 1986a, b; White et al., 1987), but only weakly activates somatodendritic autoreceptor mechanisms to diminish A10 DA neuronal impulse flow. In fact, during cocaine administration, NAc-VTA inhibitory feedback processes are required to compensate, albeit still only partially, for increased postsynaptic 
transmission. Thus, the net effect of cocaine may be an even greater enhancement of mesoaccumbens DA transmission as compared to that of other DA agonists. This hypothesis may account for the extremely potent rewarding effects of cocaine as compared to other drugs of abuse (Wise, 1984; White et al., 1987). Moreover, the almost total lack of inhibition of antidromically identificd mesocortical (mPFC) DA cells by intravenous cocaine (White et al., 1987) suggests that enhanced DA transmission within the mesocortical DA system may be even less well-compensated by diminished impulse flow, owing to the relative lack of impulse-regulating DA autoreceptors on these neurons (Bannon and Roth, 1983; Chiodo et al., 1984; White and Wang, 1984a). Obviously, studies of the effects of cocaine within the MPFC are of considerable importance, given the speculated role of this system in the initiation of cocaine-induced reward (Goeders and Smith, 1986). Such studies should help to shed light on the relationship between alterations in relevant neuronal activities and the reinforcing efficacy of cocaine and other important drugs of abuse.

\section{References}

Andén, N. E., A. Dahlström, K. Larsson, L. Olson, and U. Ungerstedt (1966) Ascending monoamine neurons to the telencephalon and diencephalon. Acta Physiol. Scand. 67: 313-326.

Andén, N. E., M. Grabowska-Andén, S. Lindgren, and U. Thornström (1983) Synthesis rate of dopamine: Difference between corpus striatum and limbic system as a possible explanation of variations in reactions to drugs. Naunyn Schmiedebergs Arch. Pharmacol. 323: 193-198.

Bagchi, S. P., and M. A. Rielly (1983) Intraneuronal dopaminergic action of cocaine and some of its metaholites and analogs. Neuropharmacology 22: 1289-1295.

Bannon, M. J., and R. H. Roth (1983) Pharmacology of mesocortical dopamine neurons. Pharmacol. Rev. 35: 53-68.

Beart, P. M., and D. McDonald (1980) Neurochemical studies of the mesolimbic dopaminergic pathway: Somatodendritic mechanisms and GABAergic neurons in the rat ventral tegmentum. J. Neurochem. 34: 1622-1629.

Björklund, A., and O. Lindvall (1975) Dopamine in dendrites of rat substantia nigra neurons: Suggestions for a role in dendritic terminals. Brain Res. 83: 531-537.

Brodie, M. S., and T. V. Dunwiddie (1986) The effects of cocaine on ventral tegmental area spontaneous activity in vitro: Interactions with dopamine, sulpiride and cholecystokinin. Soc. Neurosci. Abstr. 12. 233.

Bunney, B. S., and G. K. Aghajanian (1976) $d$-Amphetamine-induced inhibition of central dopaminergic neurons: Mediation by a striatonigral feedback pathway. Science 192: 391--393.

Bunney, B. S., J. R. Walters, R. H. Roth, and G. K. Aghajanian (1973) Dopaminergic neurons: Effect of antipsychotic drugs and amphetamine on single cell activity. J. Pharmacol. Exp. Ther. 135: 560-571.

Carlsson, A. (1975) Receptor-mediated control of dopamine metabolism. In Pre- and Postsynaptic Receptors, E. Usdin and W. E. Bunney, Jr., eds., pp. 49-65, Dekker, New York.

Carlsson, A., M. Lindqvist, and T. Magnusson (1957) 3,4-Dihydroxyphenylalanine and 5-hydroxytryptophan as reserpine antagonists. Nature 180: 1200-1203.

Carney, T. P. (1955) Alkaloids as local anesthetics. In The Alkaloids, Vol. V: Pharmacology, R. N. F. Manske, ed., pp. 211-223, Academic, New York.

Chéramy, A., V. Leviel, and J. Glowinski (1981) Dendritic release of dopamine in the substantia nigra. Nature 289: 537-542.

Chiodo, L. A., and B. S. Bunney (1984) Effects of dopamine antagonists on midbrain dopamine cell activity. In Catecholamines: Neuropharmacology and Central Nervous System-Theoretical Aspects, E. Usdin, A. Carlsson, A. Dahlström, and J. Engel, eds., pp. 369-391, Liss, New York.

Chiodo, L. A., M. J. Bannon, A. A. Grace, R. H. Roth, and B. S. Bunney (1984) Evidence for the absence of impulse-regulating somatodendritic and synthesis-modulating nerve terminal autoreceptors on sub- populations of mesocortical dopamine neurons. Neuroscience 12:116.

Creese, I., D. R. Sibley, M. W. Hamblin, and S. E. Leff (1983) The classification of dopamine receptors: Relationship to radioligand binding. Annu. Rev. Neurosci. 6: 43-71.

deWit, H., and R. A. Wise (1977) Blockade of cocaine reinforcement in rats with the dopamine receptor blocker pimozide but not with the noradrenergic blockers phentolamine or phenoxybenzamine. Can. J. Psychol. 31: 195-203.

Fischman, M. W., C. R. Schuster, and Y. Hatano (1983) A comparison of the subjective and cardiovascular effects of cocaine and lidocaine in humans. Pharmacol. Biochem. Behav. 18: 123-127.

Fuller, J. H., and J. D. Schlag (1976) Determination of antidromic stimulation by the collision test: Problems of interpretation. Brain Res. 112: 283-298.

Geffen, L. B., T. M. Jessel, A. C. Cuello, and L. L. Iversen (1976) Release of dopamine from dendrites in rat substantia nigra. Nature 260: 258-260.

German, D. C., M. Dalsass, and R. S. Kiser (1980) Electrophysiological examination of the ventral tegmental (A10) area in the rat. Brain Res. 181: 191-197.

Gessa, G. L., F. Muntoni, V. Boi, and G. Mereu (1985) Effects of ethanol on mid-brain DA and non-DA neurons. Soc. Neurosci. Abstr. 11: 300 .

Goeders, N. E., and J. E. Smith (1983) Cortical dopaminergic involvement in cocaine reinforcement. Science 221: 773-775.

Goeders, N. E., and J. E. Smith (1986) Reinforcing properties of cocaine in the medial prefrontal cortex: Primary action on presynaptic dopaminergic terminals. Pharmacol. Biochem. Behav. 25: 191-199.

Grace, A. A., and B. S. Bunney (1983a) Intracellular and extracellular electrophysiology of nigral dopaminergic neurons. 1. Identification and characterization. Neuroscience 10:301-315.

Grace, A. A., and B. S. Bunney (1983b) Intracellular and extracellular electrophysiology of nigral dopaminergic neurons. 3. Evidence for electrotonic coupling. Neuroscience 10:333-348.

Grace, A. A., and B. S. Bunney (1985) Opposing effects of striatonigral feedback pathways on midbrain dopamine cell activity. Brain Res. 333: 271-284.

Groves, P. M., and J. C. Linder (1983) Dendro-dendritic synapses in substantia nigra: Descriptions based on analyses of serial section. Exp. Brain Res. 49: 209-217.

Groves, P. M., C. J. Wilson, S. J. Young, and G. V. Rebec (1975) Selfinhibition by dopaminergic neurons. Science 190: 522-529.

Gysling, K., and R. Y. Wang (1983) Morphine-induced activation of A10 dopamine neurons in the rat. Brain Res. 277: 119-127.

Heikkila, R. E., and L. Manzino (1984) Behavioral properties of GBR12909, GBR-13069, and GBR-13098: Specific inhibitors of dopamine uptake. Eur. J. Pharmacol. 103: 241-248.

Heikkila, R. E., H. Orlansky, and G. Cohen (1975) Studies on the distinction between uptake inhibition and release of ${ }^{[3 \mathrm{H}]}$ dopamine in rat brain tissue slices. Biochem. Pharmacol. 24: 847-852.

Hökfelt, T., A. Ljungdahl, K. Fuxe, and O. Johansson (1974) Dopamine nerve terminals in the limbic cortex: Aspects of the dopamine hypothesis of schizophrenia. Science $184: 177-179$.

Imperato, A., and G. Di Chiara (1986) Preferential stimulation of dopamine release in the nucleus accumbens of frecly moving rats by ethanol. J. Pharmacol. Exp. Ther. 239: 219-228.

Koe, B. K. (1976) Molecular geometry of inhibition of the uptake of catecholamines and serotonin in synaptosomal preparations of rat brain. J. Pharmacol. Exp. Ther. 199: 649-661.

Korf, J., M. Zieleman, and B. H. C. Westerink (1976) Dopamine release in the substantia nigra? Nature 260: 257-258.

Kozell, N. J., and E. H. Adams (1986) Epidemiology of drug abuse: An overview. Science 234: 970-974.

Lindvall, O., A. Björkland, R. Y. Moore, and U. Stenevi (1974) Mesencephalic dopamine neurons projecting to neocortex. Brain Res. 81: 325-331.

Martin-Iverson, M. T., R. Ortman, and H. C. Fibiger (1985) Place preference conditioning with methylphenidate and nomifensine. Brain Res. 332: 59-67.

Martin-Iverson, M. T., C. Szostak, and H. C. Fibiger (1986) 6-Hydroxydopamine lesions of the medial prefrontal cortex fail to influence intravenous self-administration of cocaine. Psychopharmacology 88 : 310-314.

Matthews, R. T., and D. C. German (1984) Electrophysiological evi- 
dence for excitation of rat ventral tegmental area dopamine neurons by morphine. Neuroscience $11: 617-625$.

Mucha, R. F., D. van der Kooy, M. O'Shaughnessy, and P. Bucenieks (1982) Drug reinforcement studied by the use of place conditioning in rat. Brain Res. 243: 91-105.

Nauta, W. J. H., G. P. Smith, R. L. M. Faull, and V. B. Domesick (1978) Efferent connections and nigral afferents of the nucleus accumbens septi in the rat. Neuroscience 3: 385-401.

Nicoll, R. A., G. R. Siggins, N. Ling, F. E. Bloom, and R. Guillemin (1977) Neuronal actions of endorphins and enkephalins among brain regions: A comparative microiontophoretic study. Proc. Natl. Acad. Sci. USA 74: 2584-2588.

O'Brien, D. P., and F. J. White (1987) Inhibition of non-dopamine cells in the ventral tegmental area by benzodiazepines: Relationship to A10 dopamine cell activity. Eur. J. Pharmacol. (in press).

Paxinos, G., and C. Watson (1986) The Rat Brain in Stereotaxic Coordinates, Academic, New York.

Phillipson, O. T. (1979) Afferent projections to the ventral tegmental area of Tsai and interfascicular nucleus: A horseradish peroxidase study in the rat. J. Comp. Neurol. 187: 117-144.

Pitts, D. K., and J. Marwah (1987) Electrophysiological actions of cocaine on noradrenergic neurons in rat locus ceruleus. J. Pharmacol. Exp. Ther. 240: 345-351.

Risner, M. E., and B. E. Jones (1976) Role of noradrenergic and dopaminergic processes in amphetamine self-administration. Pharmacol. Biochem. Behav. 5: 477-482.

Risner, M. E., and B. E. Jones (1980) Intravenous self-administration of cocaine and norcocaine by dogs. Psychopharmacology 71:83-89.

Ritchie, J. M., and N. M. Greene (1980) Local anesthetics. In The Pharmacological Basis of Therapeutics, A. Goodman-Gilman, L. S. Goodman, and A. Gilman, eds., pp. 300-320, Macmillan, New York.

Roberts, D. C. S., and G. F. Koob (1982) Disruption of cocaine selfadministration following 6-hydroxydopamine lesions of the ventral tegmental area in rats. Pharmacol. Biochem. Behav. 17: 901-904.

Roberts, D. C. S., M. E. Corcoran, and H. C. Fibiger (1977) On the role of ascending catecholaminergic systems in intravenous selfadministration. Pharmacol. Biochem. Behav. 6: 615-620.

Roberts, D. C. S., G. F. Koob, P. Klonoff, and H. C. Fibiger (1980) Extinction and recovery of cocaine self-administration following 6-hydroxydopamine lesions of the nucleus accumbens. Pharmacol. Biochem. Behav. 12: 781-787.

Ross, S. B., and A. L. Renyi (1967a) Accumulation of tritiated 5-hydroxytryptamine in brain slices. Life Sci. 6: 1407-1415.

Ross, S. B., and A. L. Renyi (1967b) Inhibition of the uptake of tritiated catecholamines by antidepressant and related agents. Eur. J. Pharmacol. 2: 181-186.

Roth, R. H. (1979) Dopamine autoreceptors: Pharmacology, function and comparison with postsynaptic dopamine receptors. Commun. Psychopharmacol. 3: 432-445.

Salmoiraghi, G. C., and F. Weight (1967) Micromethods in neuropharmacology: An approach to the study of anesthetics. Anesthesiology 23: 54-63.

Scheel-Kruger, J., C. Braestrup, M. Nielson, K. Golembiowska, and E Mogilnicka (1977) Cocaine: Discussion on the role of dopamine in the biochemical mechanisms of action. In Cocaine and Other Stimulants, E. H. Ellinwood and M. M. Kilbey, eds., pp. 373-407, Plenum, New York.

Schwartz, R., T. Hökfelt, K. Fuxe, G. Jonsson, M. Goldstein, and L. Terenius (1979) Ibotenic acid induced neuronal degeneration: A morphochemical study. Exp. Brain Res. 37: 199-216.

Snyder, S. H., and J. T. Coyle (1969) Regional differences in $\left[{ }^{3} \mathrm{H}\right]-$ dopamine uptake into rat brain homogenates. J. Pharmacol. Exp. Ther. 165: 78-86.

Spealman, R. D., and R. T. Kelleher (1981) Self-administration of cocaine derivatives by squirrel monkeys. J. Pharmacol. Exp. Ther. 216: 532-536.

Tasaki, K., Y. Tsukahara, S. Ito, M. F. Wayner, and W. Y. Yu (1968) A simple, direct and rapid method for filling microelectrodes. Physiol. Behav. 3: 1009-1010.

Taylor, R. E. (1959) Effect of procaine on electrical properties of squid axon membrane. Am. J. Physiol. 196: 1071-1078.

Thierry, A. M., G. Blanc, A. Sobel, L. Stinus, and J. Glowinski (1973) Dopaminergic terminals in the rat cortex. Science 182: 499-501.

Ungerstedt, U. (1971) Stereotaxic mapping of the monoamine pathways in the rat brain. Acta Physiol. Scand. (Suppl.) 367: 1-48.
Van der Zee, P., H. S. Koger, J. Gootjes, and W. Hespe (1980) Aryl 1,4-dialk(en)ylpiperazines as selective and very potent inhibitors of dopamine uptake. Eur. J. Med. Chem. 15: 363-370.

Waddington, J. L., and A. L. Cross (1978) Neurochemical changes following kainic acid lesions of the nucleus accumbens: Implications for a GABAergic accumbal-ventral tegmental pathway. Life Sci. 22: 1011-1014.

Walaas, I., and F. Fonnum (1980) Biochemical evidence for gammaaminobutyrate containing fibers from the nucleus accumbens to the substantia nigra and ventral tegmental area in the rat. Neuroscience 5: 63-72.

Wang, R. Y. (1981a) Dopaminergic neurons in the rat ventral tegmental area. I. Identification and characterization. Brain Res. Rev. 3: $123-140$.

Wang, R, Y. (1981b) Dopaminergic neurons in the rat ventral tegmental area. II. Evidence for autoregulation. Brain Res. Rev. 3: 141151

Wang, R. Y. (1981c) Dopaminergic neurons in the rat ventral tegmental area. III. Effects of $d$ - and $l$-amphetamine. Brain Res. Rev. 3: 153-165.

Wassef, M., A. Berod, and C. Sotelo (1981) Dopaminergic dendrites in the pars reticulata of the rat substantia nigra and their striatal input. Combined immunocytochemical localization of tyrosine hydroxylase and anterograde degeneration. Neuroscience 6: 2125-2139.

Waszczak, B. L., and J. R. Walters (1980) Intravenous GABA agonist administration stimulates firing of Al0 dopaminergic neurons. Eur. J. Pharmacol. 66: 141-144.

White, F. J. (1986a) Comparative effects of LSD and lisuride: Clues to specific hallucinogenic drug actions. Pharmacol. Biochem. Behav. 24: $365-379$

White, F. J. (1986b) Electrophysiological effects of cocaine in the mesoaccumbens dopamine system: Studies in the nucleus accumbens. Soc. Neurosci. Abstr. 12: 1516.

White, F. J., and R. Y. Wang (1983a) Comparison of the effects of chronic haloperidol treatment on $\mathrm{A} 9$ and $\mathrm{A} 10$ dopamine neurons in the rat. Life Sci. 32: 983-993.

White, F. J., and R. Y. Wang (1983b) Comparison of the effects of LSD and lisuride on A10 dopamine neurons in the rat. Neuropharmacology 22: 669-676.

White, F. J., and R. Y. Wang (1984a) Al0 dopamine neurons: Role of autoreceptors in determining firing rate and sensitivity to dopamine agonists. Life Sci. 34: 1161-1170.

White, F. J., and R. Y. Wang (1984b) Pharmacological characterization of dopamine autoreceptors in rat ventral tegemental area: $\mathrm{Mi}$ croiontophoretic studies. J. Pharmacol. Exp. Ther. 231: 275-280.

White, F. J., and R. Y. Wang (1986) Electrophysiological evidence for the existence of both $\mathrm{D}-1$ and D-2 dopamine receptors in the rat nucleus accumbens. J. Neurosci. 6: 274-280.

White, F. J., S. R. Wachtel, P. A. Johansen, and L. C. Einhorn (1987) Electrophysiological studies in the rat mesoaccumbens dopamine system: Focus on dopamine receptor subtypes, interactions, and the effects of cocaine. In Neurophysiology of Dopaminergic Systems: Current Status and Clinical Perspectives, L. A. Chiodo and A. S. Freeman, eds. (in press), Lakeshore, Detroit, MI.

Williams, N., D. H. Clouet, A. L. Misra, and S. Mule (1977) Cocaine and metabolites: Relationships between pharmacological activity and inhibitory action on dopamine uptake into striatal synaptosomes. Prog. Neuro-Psychopharmacol. 1: 265-269.

Wilson, C. J., P. M. Groves, and E. Fifkova (1977) Monoaminergic synapses including dendrodentritic synapses in the rat substantia nigra. Exp. Brain Res. 30: 161-174.

Winer, B. J. (1971) Statistical Principles in Experimental Design, pp. 191-201, McGraw-Hill, New York

Wise, R. A. (1980) Actions of drugs of abuse on brain reward systems. Pharmacol. Biochem. Behav. 13: 213-223.

Wise, R. A. (1984) Neural mechanisms of the reinforcing actions of cocaine. Natl. Inst. Drug Abuse Res. Monogr. Ser. 50: 15-33.

Wolfe, P., H. R. Olpe, D. Avrith, and H. L. Haas (1978) GABAergic inhibition of neurons in the ventral tegmental area. Experientia 34: 73-74.

Wong, D. T., J. S. Horng, F. P. Bymaster, K. L. Hauser, and B. B. Molloy (1974) A selective inhibitor of serotonin uptake: Lilly 110140 , 3-( $p$-trifluoromethylphenoxy)- $N$-methyl-3-phenylpropylamine. Life Sci. 15: 471-479.

Yim, C. Y., and G. J. Mogenson (1980) Effect of picrotoxin and 
nipecotic acid on inhibitory response of dopaminergic neurons in the ventral tegmental area to stimulation of the nucleus accumbens. Brain Res. 199: 466-472.

Yokel, R. A., and R. A. Wise (1978) Amphetamine type reinforcement by dopamine agonists in the rat. Psychopharmacology 58: 289-296. Yoon, K.-W. P., G. L. Gessa, V. Boi, L. Naes, G. Mereu, and T. C. Westfall (1986) Electrophysiological effects of nicotine on dopamine mid-brain neurons. Soc. Neurosci. Abstr. 12: 1514. 